\title{
El patrón maquilador-exportador mexicano en la reestructuración internacional de la industria automotriz
}

\section{MATEO CROSSA*}

La industria del automóvil en México se especializa en los fragmentos de la cadena productiva internacional más intensos en el uso de la fuerza de trabajo. El país participa como una plataforma productiva de dicha industria, volcada al mercado estadounidense y excluida tecnológicamente. En contraste, lo que impera es la precariedad del mercado laboral.

* Estudiante,

Doctorado en

Estudios del Desarrollo,

Universidad

Autónoma

de Zacatecas,

y Doctorado

en Estudios

Latinoamericanos,

Universidad

Nacional Autónoma de México

\section{Introducción}

Al recurrir al caso de la industria del automóvil en México, este trabajo muestra que el patrón exportador vigente y dominante se ha desarrollado sobre la base de una creciente especialización productiva controlada por grandes capitales multinacionales, a la vez que ha excluido a la economía nacional del control en el diseño y la innovación de los procesos productivos y ha precarizado el mercado laboral de forma extensiva e intensiva. Ello ha provocado que el precio bajo de la mano de obra sea el elemento más atractivo para las inversiones extranjeras. Al respecto, se examina el mundo laboral dentro de la industria de autopartes para dar cuenta que el patrón exportador en México es sostenido por la superexplotación del trabajo que, lejos de representar desarrollo, representa desarrollo del subdesarrollo.

En la primera parte se describe el proceso de reestructuración de esa industria y la formación de cadenas productivas norteamericanas, a las que México se articula como el eslabón más débil y se le excluye de las etapas correspondientes al control intelectual del proceso productivo, del diseño y la innovación, y de las etapas de producción de mayor valor agregado. En la segunda parte se evidencia que el protagonismo que ha tenido la industria en el país es resultado de una inserción dependiente a la economía mundial que deforma el aparato productivo nacional al grado de especializarlo en pocos eslabones de la cadena de producción automotora en la que se requiere un mayor uso intensivo de fuerza de trabajo.

\section{Formación de cadenas norteamericanas de la industria del automóvil}

Desde inicios del siglo XX hasta la crisis capitalista de los 1970, la industria del automóvil estuvo basada en una lógica de integración vertical en la que todas las etapas productivas, de las primarias hasta las manufactureras -incluso las comerciales-, eran gestionadas bajo 
un único plan administrativo. El tradicional modelo fordista, que comenzó poco antes de la Primera Guerra Mundial y adquirió profundo dinamismo por su papel activo durante los dos conflictos, tenía el principio esencial de internalizar el manejo empresarial mediante una concentración territorial de una industria a las órdenes de un solo dueño. En ese modelo todo el proceso productivo estaba integrado en líneas de producción continuas. En el caso estadounidense, la industria terminal y de proveeduría de autopartes se ubicaba fundamentalmente en Michigan y sus zonas aledañas. El ejemplo insigne del modelo fue Ford River Rouge Complex creado en 1917 en Dearborn, Michigan, que contaba con la fábrica integrada más grande del mundo (2.4 km de ancho y 1.6 km de largo). El objetivo de Ford era conseguir una condición de autosuficiencia completa en toda la cadena productiva y controlar minas de carbón y hierro, canteras de piedra caliza, hectáreas de bosques para las plantaciones de caucho, líneas de ferrocarril y la central de abastecimiento de energía eléctrica para la planta. ${ }^{1}$

A partir de los 1970 el modelo de integración vertical cambió. Debido a la profundiza-

${ }^{1}$ Bryan Ford Richardson, Rouge: pictured in its prime, Detroit, Wayne State University Press, 2003. Un caso emblemático de la integración vertical fordista fueron las plantaciones de caucho cultivadas en 20 mil hectáreas de la selva amazónica para abastecer de hule a las plantas de Michigan. Esta región se denominó «Fordlandia», Eduardo Sguiglia, Fordlandia: un oscuro paraíso, Buenos Aires, Siruela, 1997. ción de la competencia mundial capitalista en el ramo automotor el modelo fordista transitó por una etapa de agotamiento que originó su transformación. Desde los 1960 la producción automotriz japonesa comenzó a crecer exponencialmente y a ganar una cuota sustancial del mercado estadounidense. La producción de vehículos en Japón organizada alrededor del modelo toyotista pasó de 300 mil unidades en 1960 a casi 11 millones en 1982. Su crecimiento ocurrió sobre la base del mercado nacional japonés que absorbía 5 millones de unidades y por las elevadas exportaciones destinadas sobre todo al mercado estadounidense. ${ }^{2}$ El notable éxito de la estrategia de exportación de los japoneses resultó en la cooptación de una mayor cuota de mercado estadounidense en detrimento de las Tres Grandes (Ford, General Motors, Chrysler).

Como respuesta a la creciente competencia de la producción japonesa, el Estado estadounidense reaccionó con la implementación de cuotas arancelarias a las importaciones de automóviles asiáticos con el fin de proteger a las Tres Grandes. Sin embargo, este proteccionismo fue contraproducente para sus empresas, pues para evadir cuotas de importación los fabricantes japoneses construyeron plantas en Estados Unidos durante la década de 1980, al grado que en 1995 fabricaban en ese país dos

2 Stephen Blank, Driving continental integration: auto manufacturing and the future of North America, Kingston, McGill-Queen's University Press, 1993.
Complejo industrial Ford River Rouge Complex creado en 1917 en Dearborn, Michigan.

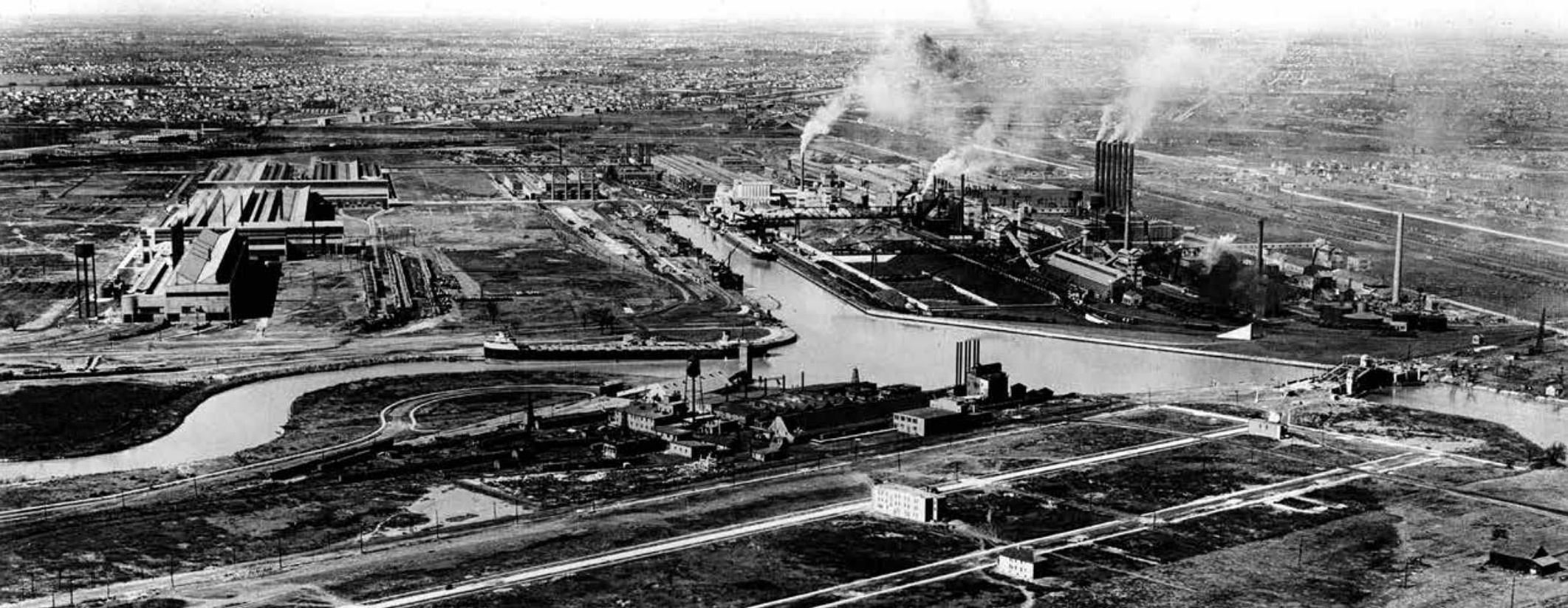




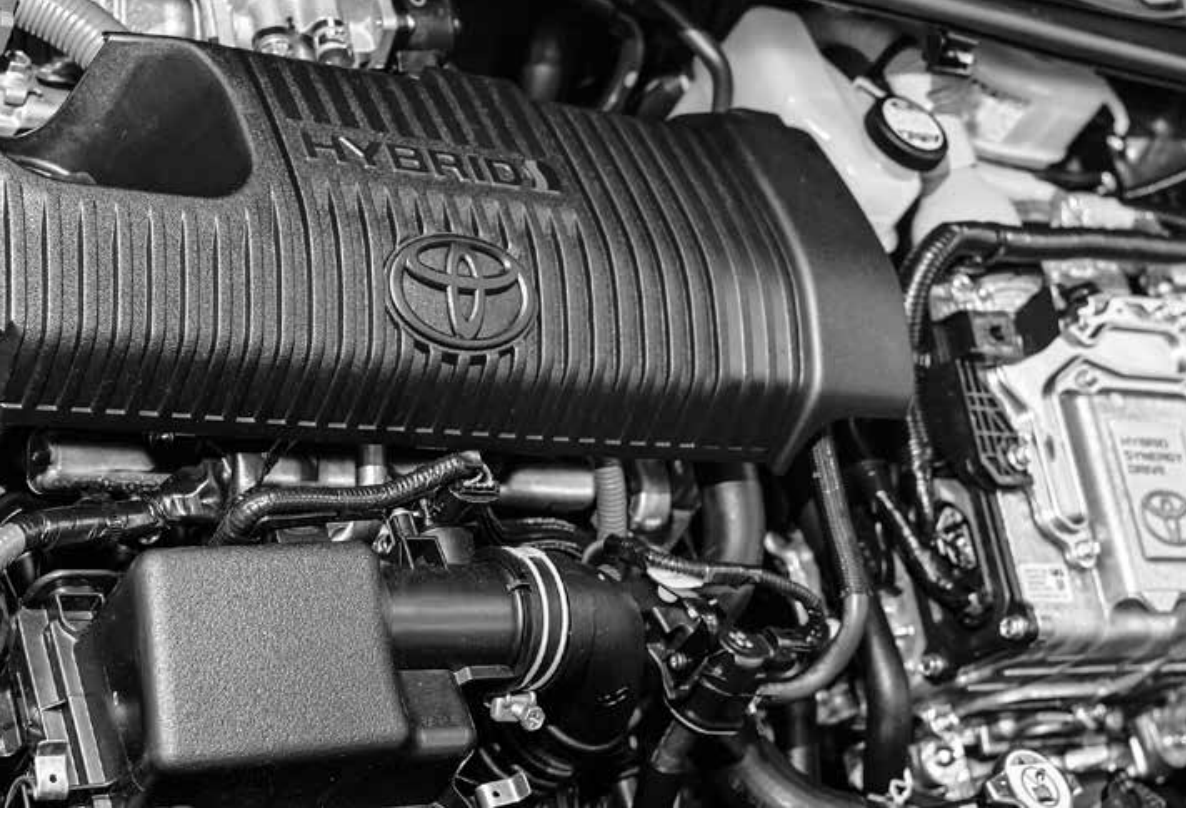

La década de 1990 destacó por la creciente y notable competencia de las empresas japonesas, por lo que se diversificó la producción de carros que implicó una revolución científico-tecnológica de la industria.

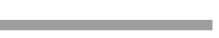

tercios de los vehículos de pasajeros que vendían en el mismo. ${ }^{3}$

Este ambiente de agitada competencia entre los grandes capitales generó una transformación profunda del rompecabezas productivo. Desde los 1980 el mercado estadounidense de automóviles se encuentra estancado con un promedio de 16 millones de carros vendidos al año, de manera que las empresas automotrices empezaron una guerra por cooptar las ventas. ${ }^{4}$ Bajar los precios de los automóviles en este contexto hubiera sido posible mediante el aumento de la producción. Sin embargo, dicho incremento hubiera significado una crisis de sobreproducción terminal para las empresas estadounidenses, tomando en cuen-

\footnotetext{
${ }^{3}$ Timothy Sturgeon, Johannes van Biesebroeck y Gary Gereffi, «Value chains, networks and clusters: reframing the global automotive industry», Journal of Economic Geography, vol. 8, núm. 3, 2008, pp. 297-321. Actualmente, las empresas japonesas se ubican en las zonas estadounidenses con baja densidad de población sindicalizada y se caracterizan, según algunos estudios, por ser las que pagan menores salarios en el país. Una muestra de que son reticentes al sindicalismo estadounidense es la larga lucha del United Automobile Workers (UAW) por sindicalizar la planta de Toyota más productiva ubicada en Georgtown, Kentucky. Kimberly Rogers y Gary Gereffi, «U.S. and Japanese lead firms' production strategies and labor in the North American automotive industry», trabajo presentado en la 102nd annual meeting of the American Sociological Association, New York, 2007.

${ }^{4}$ James Rubenstein, Making and selling cars: innovation and change in the U.S. automotive industry, Baltimore, Johns Hopkins University Press, 2001.
}

ta que los salarios se han estancado desde los 1970, al igual que la venta de carros. De hecho, la guerra de precios en la que las firmas automotrices compiten por las ventas a través de la reducción del precio final no ha sido común, salvo en contadas ocasiones. ${ }^{5}$

En vez de elevar la producción y bajar los precios, las corporaciones automotoras tomaron otro camino. Promovieron la diversificación productiva con el propósito de subordinar la esfera industrial al interés último del consumidor. De esa forma abandonaron el lema «just in case» (por sí acaso), en el que la esfera productiva controlaba a la comercial, para adoptar el lema «just in time» (justo a tiempo), en el que la esfera industrial queda subordinada a la comercial. ${ }^{6}$ Cabe resaltar el impulso de las Tres Grandes por ampliar significativamente la oferta de modelos de automóviles para competir en el mercado automotor estadounidense. En los 1950, cuando las Tres Grandes controlaban 95 por ciento del mercado, producían únicamente 30 modelos. No obstante, en la década de 1990, años marcados por la creciente y notable competencia japonesa, ofertaban varios cientos de modelos. ${ }^{7}$

La diversificación de la producción de carros implicó una revolución científico-tecnológica que motivó una profunda transformación internacional de la industria. Es preciso aclarar que tras concentrarse geográficamente dentro de los parámetros del modelo fordista, la industria se atomizó y distendió en una red de productores subcontratados y dispersos espacialmente que abastecen a las firmas. Estas últimas mantienen el control de las etapas estratégicas de las cadenas productivas (diseño,

\footnotetext{
5 Timothy Bresnahan, «Competition and collusion in the American automobile industry: The 1955 Price War», Journal of Industrial Economics, vol. 35, núm 4, 1987, pp. 457-482.

6 Gary Gereffi, «Las cadenas productivas como marco analítico para la globalización», Problemas del Desarrollo, vol. 32, núm. 125, 2001, pp. 9-37.

${ }^{7}$ James Rubenstein, op. cit.
} 
ensamble, producción de motores y comercialización), mientras que la proveeduría de autopartes se fragmenta en una red de productores que operan bajo el mando de las grandes corporaciones automotrices. Este proceso dual de concentración de capital y distensión productiva, también conocido como desintegración vertical, se convirtió en el nuevo modelo de organización productiva de la industria. ${ }^{8}$

Dentro de la reestructuración de la arquitectura industrial, las etapas de planificación, diseño e innovación controladas por las firmas automotrices se concentran en las economías desarrolladas, al igual que los eslabones más automatizados y productores de mayor valor agregado. Mientras tanto, las etapas más intensas en el uso de la fuerza de trabajo se ubican en economías subdesarrolladas debido a la reducción en los costos de mano de obra. En Estados Unidos ha sido evidente la concentración de actividades de investigación y desarrollo (I+D) en corredores industriales de ingeniería que se dedican al diseño e innovación de la industria del automóvil. Casos notables son Detroit y Sillicon Valley, que se han transformado en los centros de diseño e innovación más importantes de la industria en ese país, a la par que aglutinan las etapas productivas más automatizadas de la cadena industrial. ${ }^{9}$

En contraste, México ha sido excluido del diseño y la innovación, pero se articula al mercado estadounidense como exportador de autopartes y ensambles caracterizados por la menor automatización y el poco valor agregado en la cadena regional. Por ende, México se integra a las cadenas internacionales mediante la producción de los segmentos que demanda un alto contenido laboral. En ese sentido, destaca la producción de partes eléctricas (arneses), asientos y pequeños motores. Dichas etapas forman parte de la

\footnotetext{
${ }^{8}$ Gary Gereffi, John Humphrey y Timothy Sturgeon, «The governance of global value chains», Review of International Political Economy, vol. 12, núm. 1, 2005, pp. 78-104.

${ }^{9}$ Timothy Sturgeon, Johannes van Biesebroeck y Gary Gereffi, op. cit.
}

industria maquiladora. También es notorio el ensamble de automóviles en el que el proceso de producción no se ha automatizado y por tanto requiere un uso intensivo de mano de obra (por ejemplo, Ford F-Series), o bien automóviles pequeños, escasamente equipados, que ofrecen poco margen de ganancia por unidad para las empresas ensambladoras (como Ford Fiesta, Nissan Versa, Honda Fit). Tales etapas productivas componen la industria automotriz terminal, aunque de modo acertado Cypher y Delgado la nombran maquiladora encubierta, por la exigua articulación nacional que entraña su dinámica en el país. ${ }^{10}$

Al integrarse en el mercado estadounidense, desde las etapas menos automatizadas y más intensas en el uso de la fuerza de trabajo, México constituye un espacio productivo contratendencial a la caída de la tasa de ganancia. Es decir, en un contexto de alta competencia capitalista, que acelera el desarrollo de fuerzas productivas, precipita la incorporación de ciencia y tecnología a las mercancías y reduce el margen de ganancia de grandes corporaciones automotrices, el capital acude al uso intensivo de la fuerza de trabajo como mecanismo para suavizar la caída de la tasa de ganancia. En consecuencia, en la guerra de las empresas automotoras por conquistar el mercado estadounidense, México interviene como reservorio de mano de obra barata usada en los procesos de producción en condiciones de alta precariedad laboral.

Este papel dependiente de la economía mexicana en las cadenas de valor de la región deforma la estructura productiva nacional, al obligarla a especializarse en la producción de segmentos de la cadena productiva con alto contenido de mano de obra. Si la motivación de las empresas automotrices y autopartes para instalarse en el país es la de ahorrar en costos laborales,

${ }^{10}$ James Cypher y Raúl Delgado Wise, México a la deriva. Génesis, desempeño y crisis del Modelo Exportador de Fuerza de Trabajo, México, Universidad Autónoma de Zacatecas/ Miguel Ángel Porrúa, 2012. 
en la economía mexicana es resultado de una especialización productiva de pocos segmentos del proceso productivo caracterizados por el uso intensivo de la mano de obra. Tampoco se encuentra articulada de forma orgánica en el territorio nacional, sino que se ubica de forma atomizada, incomunicada, para responder al mando de las empresas con casa matriz en economías desarrolladas, especialmente en Estados Unidos.

\section{Exclusión tecnológica}

Una de las primeras características que revelan la posición subordinada de la economía mexicana en las cadenas internacionales de la industria automotriz es la falta de control sobre el diseño y la innovación de los procesos. En el apartado anterior se resaltó la importancia creciente del contenido científico y tecnológico en dicha actividad productiva. Debido al contexto de diversificación de los modelos de carros, el control del conocimiento se convierte en eslabón estratégico del proceso. Sin embargo, en este escenario México se encuentra en una condición de «exclusión tecnológica».11

El crecimiento exponencial a corto plazo de la industria del automóvil en México indica un posicionamiento subordinado en las cadenas mundiales de valor. Si las altas exportaciones de automóviles hubieran sido resultado de un proceso de desarrollo endógeno de fuerzas productivas, sería posible rastrear un proceso de desarrollo de largo plazo, con planeación, intervención e impulso estatal y desarrollo de bienes nacionales de capital, como ocurrió en Corea del Sur, China y Japón. No obstante, las exportaciones han crecido explosivamente porque las fuerzas productivas y los procesos laborales fueron diseñados en el exterior para ejecutarse en el territorio nacional. ${ }^{12}$ México no participa en la cada vez más importante esfera del diseño o ingeniería inicial, ya

\footnotetext{
${ }^{11}$ Ibid.

${ }^{12}$ Salvador Medina Ramírez, «La dependencia tecnológica en México», Economía Informa (330), 2004, pp. 73-81.
}

que esta etapa de la cadena productiva se desarrolla en las economías sede de las corporaciones automotrices. En ese sentido, sí se articula a las cadenas de valor desde lo que Sturgeon denomina Complete block down model, que se refiere a un modelo en el que productos y procesos laborales están prediseñados para que el productor sólo ejecute la operación. ${ }^{13}$

Cuadro 1. Inversión en I+D en la industria del automóvil, 2008 (millones de dólares)

\begin{tabular}{ccc} 
& $\begin{array}{c}\text { I+D en industria } \\
\text { manufacturera }\end{array}$ & $\begin{array}{c}\text { I+D en industria } \\
\text { del automóvil }\end{array}$ \\
\hline México & 1.6 & 0.3 \\
Estados Unidos & 196 & 114 \\
\hline
\end{tabular}

Fuente: Elaboración propia con datos de OCDE, «Business enterprise R\&D expenditure by industry», en https://stats. oecd.org/Index.aspx?.DataSetCode=BERD_INDUSTRY

El cuadro 1 arroja la información suficiente para desmentir la noción utilizada por Blank de integración estructural del sistema de producción desarrollada con base en el caso de la industria automotriz en el área norteamericana. ${ }^{14}$ A pesar de que acierta en mostrar una dinámica regional que la industria le imprime a América del Norte, Blank no identifica la inserción diferenciada y desigual de los países, al sugerir que los tres países que componen la región se articulan como socios comerciales en igualdad de condiciones. Asimismo, deja entrever la diferencia abismal de inversión en investigación y desarrollo en los ámbitos manufacturero y automotor entre México y Estados Unidos: evidencia la pronunciada desigualdad en la invención y el control del proceso de producción entre ambos países.

\footnotetext{
${ }^{13}$ Timothy Sturgeon, Jack Daly, Stacey Frederick, Penny Bamber y Gary Gereffi, «The Philippines in the automotive global value chain», Center on Globalization, Governance \& Competitiveness, Duke University, 2016.

${ }^{14}$ Stephen Blank, «Building autos: how North America works and why Canadian studies should be interested», American Review of Canadian Studies, vol. 41, núm. 4, 2011, pp. 330-344.
} 
México invierte únicamente 3 por ciento de lo que Estados Unidos gasta en materia de investigación y desarrollo, a pesar de que la diferencia del número de trabajadores no es tan amplia entre ambos países -México tiene $780 \mathrm{mil}$ personas ocupadas y Estados Unidos 950 mil. Por tanto es posible afirmar que la inserción de México a las cadenas regionales de valor se lleva a cabo sobre la base de una dependencia tecnológica que excluye a la economía mexicana de poder decidir qué, cómo y cuándo se produce.

\section{Especialización productiva}

Un segundo elemento que demuestra el papel dependiente de México en las cadenas productivas de la industria del automóvil es la especialización productiva. Más allá de impulsar un desarrollo endógeno, el país se ha especializado en la exportación de fragmentos productivos entre los que destacan algunas piezas y ensambles de carros que requieren un alto contenido de intervención de la fuerza de trabajo. Si bien hay etapas de la cadena productiva que se encuentran altamente automatizadas, existen otras que exigen intensidad en el uso de la mano de obra.

De las 780 mil personas que trabajan en la industria automotriz en México, 83 por ciento
(647 mil) se ubica en las autopartes. Las exportaciones de autopartes a Estados Unidos son 136 por ciento más que las de automóviles, lo que refleja la falta de encadenamiento nacional de la industria. Dentro de las autopartes destacan dos ramas que emplean a casi 60 por ciento de la población. En primer lugar está la producción de arneses, en la que se ubica 45 por ciento de la población ocupada en autopartes (281 mil personas). Es uno de los eslabones productivos menos automatizados, por lo que no es casual que México sea el mayor productor en el mundo, con 23 por ciento del total de arneses para automóviles; además de ser el mayor proveedor para el mercado estadounidense. ${ }^{15}$

En efecto, provee 61 por ciento del equipo eléctrico y electrónico importado por Estados Unidos, muy por encima de Japón (10 por ciento), China (8 por ciento) y Filipinas (4 por ciento). La segunda rama es la producción de asientos, en la que trabajan 90 mil personas (14 por ciento del total). ${ }^{16}$ Dicha rama no está altamente automatizada debido a la diversidad de insumos

\footnotetext{
15 Timothy Sturgeon, Jack Daly, Stacey Frederick, Penny Bamber y Gary Gereffi, op. cit.

${ }^{16}$ Debra Menk y Bernard Swiecki, «The growing role of Mexico in the North American automotive industry», Center for Automotive Research (CAR), 2016.
}

Cuadro 2. Remuneraciones mensuales en la industria del automóvil para la exportación (en pesos mexicanos)

\begin{tabular}{|c|c|c|c|c|c|c|c|}
\hline & 2009 & 2010 & 2011 & 2012 & 2013 & 2014 & 2015 \\
\hline Industria manufacturera & 8523 & 8855 & 9274 & 9598 & 9865 & 10372 & 10843 \\
\hline Equipo de transporte & 9555 & 9674 & 9934 & 10183 & 10306 & 10798 & 11538 \\
\hline Ensamble & 20672 & 20953 & 22174 & 22654 & 23200 & 22126 & 22836 \\
\hline Autopartes & 8145 & 8259 & 8427 & 8636 & 8937 & 9494 & 10250 \\
\hline Motores & 12202 & 12275 & 12672 & 13715 & 14375 & 15409 & 15983 \\
\hline Arneses & 7253 & 7461 & 7661 & 7678 & 8149 & 8195 & 9115 \\
\hline Direcciones y suspensiones & 9747 & 9918 & 9972 & 9831 & 10329 & 13245 & 14276 \\
\hline Frenos & 9029 & 9461 & 10638 & 11744 & 11868 & 14096 & 14392 \\
\hline Transmisiones & 11684 & 11743 & 12287 & 12745 & 11372 & 15532 & 17454 \\
\hline Asientos & 7099 & 7122 & 6533 & 7091 & 7808 & 8102 & 8273 \\
\hline Piezas metálicas troqueladas & 6916 & 6750 & 6722 & 7722 & 7763 & 6463 & 7455 \\
\hline Otras & 8013 & 8069 & 8280 & 8168 & 8368 & 8959 & 9711 \\
\hline
\end{tabular}

Fuente: elaboración propia con datos del Instituto Nacional de Estadística, Geografía e Informática (INEGI, 2017). 
Gráfica 1. Ocupación de personal en fabricación de autopartes

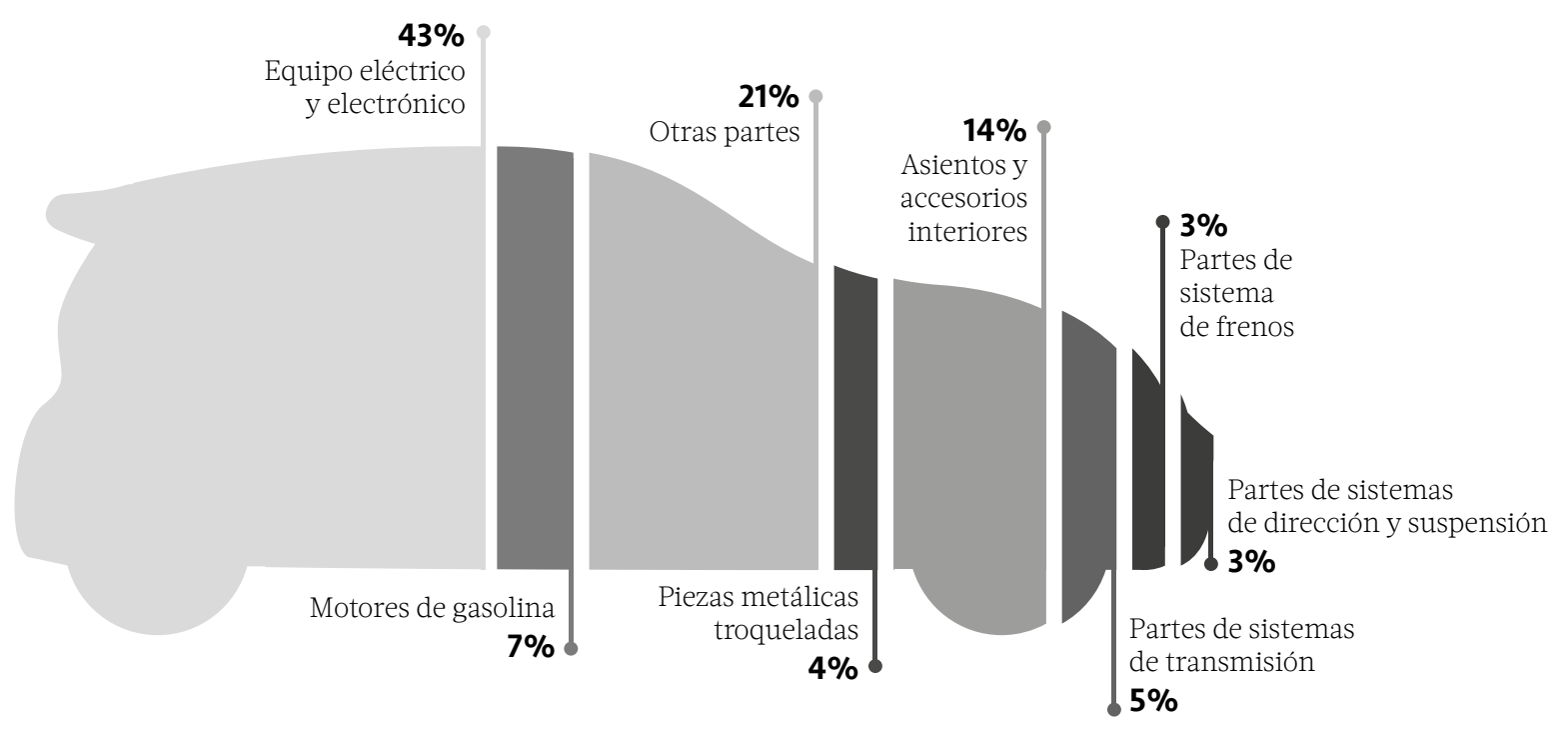

Fuente: Elaboración propia con datos de INEGI, «Remuneraciones mensuales en la industria del automóvil para la exportación», 2017.

que implica su ensamble y por la complejidad de operaciones.

El grado de concentración de trabajadores en la producción de arneses y asientos contrasta con la baja remuneración. Las dos actividades registran las remuneraciones más bajas de toda la industria del automóvil. En el caso de la elaboración de arneses, el INEGI reporta un promedio de remuneraciones mensual de poco más de 9 mil pesos (450 dólares), mientras que en la fabricación de asientos es de cerca de 8 mil pesos (400 dólares). Las cantidades son un promedio del total de empleo, de manera que los salarios de obreros son significativamente más bajos, pues varían de 700 a mil 200 pesos semanales (equivalentes a 37 y 63 dólares, respectivamente).

No es casualidad que la producción de arneses y asientos, que emplean a la mayor cantidad de trabajadores, posee las remuneraciones más bajas. Tal combinación refleja el papel de México en las cadenas regionales norteamericanas. Por los bajos salarios, se convierte en exportador de segmentos del proceso productivo automotor más intensivos en el uso de la fuerza de trabajo. Entre menor sea el costo laboral, mayor será su ventaja competitiva en la región. Por tanto, es posible sostener que la industria de automóviles en México es un rompecabezas productivo altamente desarticulado, atomizado y mal remunerado.

\section{Conclusiones}

No se puede hablar de la industria automotriz mexicana de forma genérica, ya que esto implicaría aludir a un aparato productivo diversificado e integrado, que recorre la totalidad del proceso productivo. Por el contrario, dicha industria se concentra en pocos segmentos de la cadena productiva que sobresalen por ser los más intensos en el uso de la fuerza de trabajo. A pesar de que la industria de autopartes y ensamble de automóviles es una actividad protagónica dentro de la estructura económica nacional, se encuentra volcada al mercado estadounidense, es altamente especializada y se subordina a su dinámica industrial. En ese contexto, lo que prevalece como elemento fundamental es la precarización del mercado laboral. 